\title{
"ASPECTUS ANIMAE RATIO EST" APUNTES SOBRE LA RAZÓN EN LOS SOLILOQUIOS DE SAN AGUSTÍN
}

\author{
Almudena Jiménez Manzanas \\ Universidad de Salamanca
}

\begin{abstract}
RESUMEN
Definir el concepto de razón, determinar su modus operandi y su alcance, ha sido objeto del quehacer filosófico desde sus orígenes hasta nuestros días. Las páginas que siguen no pretenden agotar el significado de razón, ni tan siquiera en el marco de la filosofía agustiniana -dado que en el santo el término no es unívoco- sino el de ofrecer un análisis de la racionalidad, en su función cognoscitiva, señalando su relación con el alma y sus posibles objetos de conocimiento, entre ellos Dios, con el propósito implícito de aportar una perspectiva conciliatoria entre puntos de vista en cierta medida reduccionistas
\end{abstract}

Palabras clave: Razón, alma, mente, intuición, Dios.

\section{ABSTRACT}

To define the concept of reason, to determine its modus operandi and its scope has constituted the philosopher's task from its origins till today. What follows does not intend to exhaust the meaning of reason, not even within the frame of Agustinian philosophy, since the term itself is not univocal in Agustinian philosophy, but rather to offer an analysis of rationality, in its cognitive function, and point out its relationship whit the soul, and its possible objects of knowledge - God among others - and in doing so, to offer a perspective which reconciles points of view somewhat reductionist.

Keywords: Reason, soul, mind, intuition, God.

\section{EL CONCEPTO DE RAZÓN}

Abordar el concepto de razón en cualquier contexto resulta siempre una tarea en extremo complicada dada la polivalencia del término. Como bien es sabido, a lo largo de la historia del pensamiento el vocablo ha adquirido variadas significaciones e incluso hoy día no podemos, con rigor, asociarlo a un significado único, sin caer en un reduccionismo, porque realmente ninguno de ellos es excluyente y todos muestran distintos rostros de lo que la razón es.

En San Agustín la dificultad es considerable atendiendo a la frecuente ausencia de sistematicidad en sus escritos, lo que a menudo va parejo a la falta de precisión definitoria en algunos de los conceptos que emplea. Lo cual no resta profundidad a las reflexiones agustinianas. Por el contrario, la agudeza de su pensamiento es innegable. Sin emb̈argo hay que advertir este inconveniente 
que sale al paso del investigador cuando pretende aclarar y fijar ciertas nociones y es que el hiponense en numerosas ocasiones las emplea con sentidos no exactamente unívocos. En determinados fragmentos podemos apreciar cómo un vocablo adquiere un sentido ligeramente distinto al que había tenido con anterioridad, de forma que, en este camino de análisis conceptual, se hace indispensable cotejar los textos y tener muy presente el contexto. Hay que insistir, por lo demás, en que no se trata de un error o de una falta de rigor por parte del santo, sino de un ejercicio retórico: San Agustín juega con las palabras adquiriendo el lenguaje, bajo el dictado de su pluma, una plasticidad que le es propia dada su formación literaria, lo que puede chocar con un espíritu analítico poco apto para los juegos retóricos. Un ejemplo de esto se encuentra en el mismo concepto de razón.

En el libro de los Soliloquios aparece una frase tan breve como contundente y de graves implicaciones en la teoría agustiniana del conocimiento: «la razón es la mirada del alma». ${ }^{1}$ Esta expresión atestigua, además, cómo el rigor filosófico y teológico de San Agustín, adquirido de modo paulatino tras su conversión al Catolicismo, no menguó la belleza de sus escritos, por el contrario, fue aquél acicate para profundas y también líricas manifestaciones, que vienen a plasmar un pensamiento de gran hondura a través de palabras e imágenes muy sugerentes, en ocasiones recurriendo a la alegoría, en este caso estableciendo un paralelismo entre la percepción visual y el fenómeno del conocimiento. San Agustín es un ejemplo de conciliación entre contenido y forma por cuanto fue capaz de aunar la expresión bella con un pensamiento filosófico de gran profundidad.

El texto latino dice literalmente: «aspectus animae ratio est», donde aspectus admitiría dos significados que, lejos de contraponerse, se apoyan mutuamente: mirada y/o aspecto. Que la razón es la mirada del alma acentúa el carácter dinámico de aquélla como facultad de ésta, pero razón y alma desde esta perspectiva no se identificarían plenamente; podríamos decir que el alma incluye a la razón aunque se nos sugiere la idea de un excedente en lo que respecta al alma, es decir, ésta no es sólo la razón. Si traducimos aspectus por aspecto nos encontraríamos con que el alma se muestra como razón, su aspecto es la razón pero de aquí tampoco puede colegirse que alma y razón sean exactamente lo mismo pues el alma aparece como razón pero continúa vigente ese excedente de significado al que aludíamos anteriormente.

El grado de identificación entre razón y alma no se muestra lo suficientemente claro, pero resulta evidente su conexión intrínseca. Así, dice el hiponense que el alma es «una sustancia dotada de razón destinada a regir el cuerpo». ${ }^{2}$ A la luz de esta definición no puede afirmarse que razón y alma sean sinónimos hasta el punto de que ambos vocablos puedan sustituirse uno por el otro, pero sí se abunda nuevamente en la íntima conexión de éstos, de manera que hablar de alma humana implica referirse a la razón y a la inversa. Por otra parte, también se dice en Del libre albedrío que el alma racional es lo que nos distingue y nos hace superiores al resto de las criaturas, también poseedoras de un alma. ${ }^{3}$ Siendo así, la razón define, como característica discretiva y primordial, al alma humana en contraste con el resto de las almas existentes, e incluso sería ésta la facultad que nos identifica como criaturas hechas a imagen y semejanza de Dios. ${ }^{4}$

1 Soliloquios, I, 6, 12. (1946). Todas las obras citadas de San Agustín pertenecen a los volúmenes editados por la Biblioteca de Autores Cristianos, 40 vols., Madrid. Dado que las referencias han sido tomadas de diversas ediciones, a partir de ahora junto a la obra tan sólo constará el año de edición.

2 De la cuantidad el alma, 14, 23. (1971).

3 Del libre albedrío, II, 6, 13. (1971)

4 De la Stma. Trinidad, XII, 7, 12. (1948) 


\section{LA RAZÓN ES LA MIRADA DEL ALMA}

Si bien con anterioridad decíamos que aspectus admitía dos significados no contrapuestos, hemos tomado como referencia el de mirada, más apropiado en este caso por cuanto se inserta en un contexto en el que San Agustín está estableciendo un paralelismo entre el fenómeno de la visión y el de la aprehensión intelectual.

La mirada alude a una actividad, pero toda actividad ha de ir referida a un sujeto que la hace posible. En este caso la razón no es el sujeto de esa mirada sino que es la misma mirada, ¿dónde se encuentra el sujeto? Siguiendo con el texto de los Soliloquios, podría aducirse que se trata del alma entendiendo por tal el órgano - en un sentido metafórico- que proyecta esa mirada. Sin embargo más adelante se vincula la razón a la mente: «Y yo, la razón, soy para la mente como el rayo de la mirada para los ojos», 5 de modo que la función del alma se atribuye ahora a la mente. Esto no significa que alma y mente se identifiquen por completo; la mente sería una dimensión del alma en virtud de la cual conoce. Más adelante en la misma página se lee: «El ojo del alma es la mente pura de toda mancha corporal». Parece pues que, en efecto, es la mente el asiento de la razón, los ojos - para continuar con el ejemplo- y aquélla, su actividad o mirada.

En otro texto perteneciente a De la cuantidad del alma San Agustín matiza aún más esta idea diciendo que «la razón sería cierta mirada de la inteligencia y raciocinio la investigación de la inteligencia, esto es, el movimiento de esa mirada a través de las cosas que han de examinarse». ${ }^{6} \mathrm{Se}$ continúa aquí identificando a la razón con la mirada pero en esta ocasión no es atribuida a la mente sino a la inteligencia; por otro lado, el concepto de raciocinio incide más en el carácter dinámico de la facultad cognoscitiva. De acuerdo con este último fragmento puede suponerse que la mente es la inteligencia, o bien que la mente incluye a la inteligencia como término global para significar que es la mente la que posibilita el conocimiento racional. En este aspecto y empleando otro símil que, lógicamente, San Agustín no utiliza, podríamos comparar a la razón con el enfoque producido por el objetivo de una cámara fotográfica y al raciocinio con la visión efectiva que tiene lugar en virtud de ese objetivo y de ese enfoque. El objetivo fotográfico no es, según eso, otra cosa que la inteligencia, pero todo el complejo sistema óptico interior de la cámara es la mente. En definitiva, no estamos más que ante diversos conceptos que vienen a significar los distintos procesos -no separables y que se distinguen muy sutilmente- que tienen lugar en el acto de conocer. La mente es, dentro de este esquema, la dimensión del alma que comprende tanto a la inteligencia como a la razón; sin embargo, insistimos, no se trata más que de perspectivas que se refieren a una misma cosa e incluso los conceptos que se utilizan llegan en ocasiones a hacerse sinónimos; así, por ejemplo, dice San Agustín: «a pocos es permitido ver al alma por medio de la misma alma, es decir, que el alma se contemple a sí misma, pero se ve con la inteligencia», ${ }^{7}$ con lo cual se corroboraría la tesis de que la inteligencia es esa facultad que se incluye en la mente junto con la razón; y más adelante: «Y si en los sentidos corporales, que únicamente están hechos para percibir las cosas corpóreas, no influye para nada, por lo que a la potencia visiva se refiere, la magnitud del cuerpo dime:

5 Soliloquios, I, 6, 12

6 De la cuantidad del alma, 27, 53

7 De la cuantidad del alma, 14,24 
¿hemos de temer que el alma humana, cuya más preciada y casi única visión es la misma razón, con la que se ve también a sí misma, sea nada, en el supuesto de que la misma razón, es decir, la misma alma, nos convenciera de que carece de toda extensión con que ocupa el lugar?». ${ }^{8}$ Como puede apreciarse, razón e inteligencia aquí se identifican bajo el punto de vista de su capacidad para descubrir o ver al alma, lo que viene mostrar que el hiponense emplea como sinónimos términos que en otras ocasiones distingue sutilmente.

En definitiva, sintetizando las diversas lecturas que pueden hacerse del concepto de razón en su relación con el alma, cabe entender a aquélla como una facultad de ésta, una potencia con la cual conoce. Dadas estas premisas el objetivo ahora es el de mostrar qué puede conocer la razón y de qué modo.

\section{RAZÓN E INTUICIÓN}

En el capítulo primero de los Soliloquios narra San Agustín la manera como da comienzo su indagación acerca de la verdad - temática por la que discurre la obra. Se describe la situación como una interrupción en sus reflexiones acerca de sí mismo provocada por una voz de la que Agustín no sabe por de pronto su procedencia. Manifiesta, por tanto, desconcierto ante de un elemento extraño que se introduce en sus pensamientos espontáneamente y no como el resultado del proceso argumentativo. Si bien esta voz, es en principio extraña, enseguida es atribuida a la misma razón. ${ }^{9}$

El hecho de que Agustín emplee esta imagen puede ser debido, a nuestro juicio, a dos motivos que, por otra parte, no se excluyen: a un artificio retórico, o bien, a una muestra de como el concepto de razón agustiniano es lo suficientemente amplio como para que se incluya en él un peculiar carácter intuitivo que, a menudo, es distinguido y separado radicalmente de la razón.

Si la razón es lo que nos permite el conocimiento de la verdad en función de una luz emanada de la Razón Suprema o Dios, es plausible que, sin negar el proceso discursivo argumentativo que nos conduce al descubrimiento de la verdad (y de ella al conocimiento del Creador, sobre el que se asienta la naturaleza veritativa de aquélla) ésta se de intuitivamente al entendimiento previamente o incluso durante el ejercicio del razonamiento. En este caso la verdad, el resultado de la investigación, se manifestaría como pregunta, incluyendo ésta implícitamente la respuesta. Es decir, desde el primer instante en que la razón es deslumbrada por una cuestión que se le impone como objeto de reflexión y la respuesta está dada ya de antemano intuitivamente. Resulta paradójico afirmar un comienzo intuitivo del proceso argumentativo teniendo presente que por intuición se entiende un tipo de percepción directa que no es causa ni consecuencia de un razonamiento. Podría aducirse que tal proceso no sería necesario pues la respuesta o resultado de la investigación ya está dada de antemano. Sin embargo, tal suposición no responde a otra cosa que a un viejo prejuicio consistente en desligar de forma radical la intuición de la razón y que no hace justicia al modus operandi del intelecto humano en el cual se concilian, por no decir, se dan simultáneamente ambos conceptos, y no como dos momentos separados, sino como partes integrantes de un 
mismo proceso razonador. Si bien la intuición se manifiesta en un primer instante interpelando al investigador y haciéndole fijar la mirada sobre un objeto de reflexión, la intuición acompaña a todo el proceso discursivo. Aquí el lenguaje nos traiciona, puesto que hablar de proceso parece chocar con la idea de intuición, caracterizada ésta comunmente como una luz — voz en este caso- que invade de súbito y al margen del entendimiento. Sin embargo esta luz expresada como revelación no es otra cosa que la misma razón. En otros términos, intuimos la verdad bien sea en la certeza conceptual, o bien en cuanto que abre un interrogante, una duda que, al mismo tiempo, ilumina el camino a seguir para su resolución. En el texto que nos ocupa, San Agustín en el momento de ser interpelado por esa voz, se encuentra inmerso en cavilaciones y el giro que introduce es - al tiempo que una respuesta a sus pesquisas, en tanto que traza el camino a seguir para la aclaración y, por lo tanto, la solución ya se vislumbra en ella - una apertura a nuevas conjeturas. Es, en definitiva aclaratoria y, a la vez, suscitadora de nuevos interrogantes que el autor las considera ya conducentes a la solución de sus averiguaciones. La voz de la razón se le manifiesta pues al santo con estos caracteres.

Evidentemente, la noción de intuición que aquí se está manejando difiere notablemente de esa. otra, común a la mística, según la cual el verdadero conocimiento de las realidades transcendentes sólo es posible cuando la razón enmudece. La intuición aquí atribuida a San Agustín no hace referencia al silencio, ni interior ni exterior. Si el hiponense insta de continuo al recogimiento interior no es con el ánimo de lograr el silencio, al menos no en el sentido que le da la mística. Por silencio, en todo caso, habremos de entender el cerrar las puertas al mundo de modo que se permita concentración en los propios pensamientos; en pocas palabras, hay que acallar a los sentidos para que la razón hable, una razón, insistimos, iluminada por Dios que se hace presente en el razonamiento como Razón Suprema que es. En otros términos, puede afirmarse que el hombre conoce ciertas verdades únicamente porque Dios ilumina su mente capacitándole para el descubrimiento de éstas. No es otro el papel que las tres virtudes teologales (fe, esperanza y caridad) ${ }^{10}$ desempeñan en el conocimiento sino el de capacitar esa apertura mental imprescindible para que la luz divina, embargando al entendimiento, nos permita descubrir la verdad. No obstante, tal fenómeno no ha de comprenderse tampoco en un sentido cercano al misticismo. San Agustín no habla aquí como místico; por el contrario su concepción del conocimiento es eminentemente racional, en cuanto que la razón que nos lleva al conocimiento de la verdad está íntimamente ligado a una noción de Dios, como Razón Suprema, que posibilita tal conocimiento iluminando la mente, de forma sin embargo que tal iluminación no está fuera del proceso razonador. Así, la voz que San Agustín escucha interiormente es desconcertante en un principio y se pregunta el santo si su procedencia no será divina. Acto seguido y sin mediar ninguna explicación la atribuye a la razón misma; y esto es, a nuestro juicio, debido a que no existe un abismo insalvable entre lo que es la Razón Suprema y la razón del hombre. Ambas están ligadas, dándose entre ellas una semejanza o analogía que es condición sine qua non para la aprehensión de la verdad. La razón divina hace luz, ilumina. Esta iluminación posee ciertamente rasgos intuitivos, pero acontece en una razón finita que se encuentra inmersa en una deducción. Podría decirse con Pascal que todo cono- 
cimiento verdadero está integrado por un espíritu de geometría y por un espiritu de sutileza, ${ }^{11}$ entendiendo por este último el corazón, de naturaleza intuitiva y emocional, es decir, un espíritu que nos conduce a un tipo de saber que se siente. A esto habría que añadir que, como es bien sabido, el corazón no es, en rigor, un órgano de conocimiento. Con otras palabras, la vía del corazón es también una peculiar vía intelectual.

Hasta ahora se han manejado dos niveles en cuanto a la intuición se refiere y que es preciso aclarar. Intuición, en este contexto, alude a un cierto innatismo de las ideas tal que permite, mediante la autointerrogación, el desvelamiento de la verdad. Innatismo que requiere, no obstante, ser matizado. Las verdades existen de manera objetiva, más allá de toda consideración humana, porque hay un Dios que es la verdad en términos absolutos y en el cual las verdades tienen su fundamento como tal. Si esto es así, el hombre no tiene que elaborar la verdad a través de sus razonamientos sino tan sólo percatarse de ellas. En este percatarse o aprehender la verdad consiste el conocimiento, como un desvelar algo que está ahí presente pero que de algún modo se nos oculta debido a nuestra obcecación. La virtud, acompañada del uso de la razón, posibilita el conocimiento en ayuntamiento con la gracia divina, sin la cual todo intento por conocer resultaría fallido.

Así pues, la verdad junto con la posibilidad de su intelección están ahí desde siempre y de una manera primaria el hombre la percibe porque es un ser racional pero que precisa ser liberado de las limitaciones que imposibilitan su entendimiento. En esta línea San Agustín se hace eco de una idea netamente socrática y es la de que las respuestas nos las damos a nosotros mismos, ${ }^{12}$ de modo que el maestro es tan solo un guía que nos ayuda en ese autorresponderse. No resulta, por lo tanto, casual que en los Soliloquios el diálogo se establezca con la propia razón. El carácter intuitivo al que nos hemos referido alude a ese pre-percatarse de la verdad que se hace presente en la pregunta, pero también al modo como la Razón Suprema limpia los ojos de la mente permitiendo el conocimiento y a lo que San Agustín llama iluminación puesto que, como la luz del sol, baña los objetos para que los ojos puedan verlos. ${ }^{13} \mathrm{La}$ iluminación en este segundo sentido tampoco adquiere los caracteres de un arrebato místico al no salirse del plano racional, aunque incluye, no obstante, aspectos emocionales, tal como puede comprobarse en el placer provocado por el conocimiento, que San Agustín pone de manifiesto tan vivamente en sus exclamaciones de alegría y gratitud al Creador. La intuición, en el primer sentido aludido, no es más que un modo de proceder de la razón, en el segundo es un modo de proceder de Dios, sin embargo, a la postre confluyen, en virtud de su naturaleza racional, en el acto conocedor.

Por otra parte, uno de los rasgos que caracteriza a las experiencias de tipo místico es su inefabilidad, a pesar de que los grandes místicos se sintieran impulsados a expresar el contenido de sus experiencias. Y ciertamente hablaron sobre ello, pero lo hicieron por vía indirecta, acercándose al misterio simbólicamente y dando lugar a creaciones de gran calidad poética y religiosa que a posteriori se han convertido en objeto del análisis filosófico. Se entiende, sin embargo, que la plasmación de tales experiencias, bien sea oralmente o a través de escritos, implica un rebajamiento en su

11 Pascal, B. Pensamientos. Madrid, Alianza Editorial, 1981.

12 Del maestro, 11, 38 (1971); De la cuantidad del alma, 20, 34

13 Soliloquios, I, 6, 12 
veracidad y en su hondura emocional dado que la razón, de naturaleza finita y que opera fijando la realidad en el concepto, debe intervenir en ese proceso narrativo. Subyace la tesis de que lo finito no puede comprender lo infinito, lo que llevado a sus extremos, ha conducido a una lamentable dicotomía en el pensamiento, vinculando la razón a lo fáctico y dejando los temas transcendentes exclusivamente para la creencia o la fe pretendidamente irracionales. La demarcación de los límites de la razón se ha llevado con frecuencia con un rigor mal entendido, excesivamente reduccionista, dando lugar a una razón precaria que para ser legítima ha de atenerse a lo experimentable; se ha caído, en definitiva, en una visión de la racionalidad cientifista y excluyente por cuanto niega que se pueda argumentar con fundamento acerca de lo transcendente. Sin negar que abordar el tema de Dios y del alma desborda la capacidad racional (cuestión con la que San Agustín, sin duda, se muestra de acuerdo), uno de los propósitos de esta exposición es mostrar que el tema de Dios es cuando menos pensable.

San Agustín se encuentra ante un tipo de experiencias cognoscitivas puramente racionales, y en ningún modo inefables. Es más, se ve precisado a exponer por escrito sus deducciones a fin de retener las verdades conocidas, dado que confiarlas a la memoria no le ofrece garantía suficiente. Esta es la justificación primordial de la existencia del texto de los Soliloquios: la necesidad inevitable de escribir, de narrar sus investigaciones. Expone así el hiponense de manera coherente su peregrinar, a través de lúcidas argumentaciones, hacia el conocimiento del alma, de Dios y de la naturaleza de la misma verdad. Su interlocutor en este caso es la razón, se trata, por tanto, de un escrito elaborado en la más estricta soledad;hasta el punto de que no se presta el autor a transmitir estas enseñanzas a través del dictado. Precisa, por el contrario de un nuevo replegarse sobre sí mismo para revivir o reconstruir en la redacción sus experiencias cognoscitivas.

¿Puede, no obstante, la escritura provocar una reducción de la vitalidad de los argumentos? No parece ser este el caso. Por el contrario Aurelio Agustín se ve impelido a redactar ya no sólo para no olvidar y vencer así los fallos de la memoria. La redacción se presenta, además, como una forma de dotar de mayor vigor y claridad al proceso que ha tenido lugar interiormente y por medio del cual ha alcanzado ciertas verdades. Una prueba de que esto es así puede apreciarse en la plegaria a Dios, con la que inicia el diálogo, y que la razón le invita a poner por escrito, no guardándola para sí, "para darse más brío». ${ }^{14} \mathrm{La}$ escritura, sería, en este sentido, no sólo un medio de comunicación de cara a unos potenciales lectores - aunque evidentemente esta perspectiva se incluye- sino un medio de crear, recreando un proceso razonador que ya ha tenido lugar de antemano. En definitiva, la escritura es fundamental no sólo para comunicar, sino también para afianzarse más en sí mismo dilucidando los razonamientos. La necesidad de expresar atendería a una doble necesidad: la comunicativa «hazme digno de ser escuchado» ${ }^{15}$ y la autognosis, ésta última en tanto que lo que se propone Agustín es conocer el alma y a partir de este autoconocimiento acceder al conocimiento de la verdad y de Dios. 


\section{LO QUE PUEDE CONOCER LA RAZÓN}

San Agustín busca conocimientos y no creencias. Éstas últimas ya las posee pero necesita justificarlas racionalmente. Para alcanzar este conocimiento, que incluye la creencia, rechaza la concurrencia de los sentidos, pues éstos se limitan al terreno de la materialidad y a él sólo le interesa el conocimiento de las verdades de tipo transcendente, entendiéndose por ello fundamentalmente el conocimiento del alma y de Dios, dos cuestiones que como el mismo autor confiesa son las únicas que realmente le importan, ${ }^{16}$ y a las que no tiene acceso la percepción sensible. El entendimiento es pues la única facultad para conocer el alma y, si tenemos en cuenta que la naturaleza racional del alma humana es lo que nos distingue de los animales (también poseedores de alma) y Io que nos acerca al Creador (Razón Suprema) como criaturas hechas a su imagen y semejanza, la indagación acerca del alma es efectuada por la razón misma y es, nuevamente, una autognosis, puesto que conociendo al alma racional a través de la razón se descubre ella a sí misma, es decir, se conoce el hombre a sí mismo. Se trata, en definitiva, de un conocimiento de la razón a través de la razón y, por lo tanto, el objeto y el sujeto de la investigación coinciden. Si esto es así, se da lugar a una dificultad sólo aparente, y es la posibilidad de que una misma cosa pueda ser a la vez sujeto y objeto de conocimiento. ${ }^{17}$

Continuando con los textos de San Agustín cabría añadir que, del mismo modo que el ojo físico no se ve a sí mismo, es decir, sólo ve allí donde no está, ${ }^{18}$ la razón, siendo los ojos de la mente o del alma, no se ve a sí. Según esto ¿es posible el autoconocimiento? Efectivamente para San Agustín lo es -en cierto grado y con muchas dificultades- y no sólo para él; no hay que perder de vista que en este punto el hiponense está haciéndose eco del antiguo adagio griego conócete a ti mismo, como eje en torno al cual se articula el conocimiento de lo real y, por tanto, por el cual se hace posible la sabiduría. ${ }^{19} \mathrm{Se}$ trata, por lo demás, de un principio cognoscitivo de gran fecundidad en la historia de la filosofía pues, no en vano, la reflexión que en la tradición filosófica posterior ha tenido lugar sobre la razón, sus límites y capacidades, se ha llevado a cabo partiendo de la única facultad posible para este tipo de conocimiento: la misma razón; además conocer la razón es conocer al hombre o, al menos, buena parte de lo que el hombre es.

Con relación a este tema se hace patente lo que para San Agustín era una evidencia: el conocimiento sólo es posible por afinidad o simpatía. Esto significa que el objeto de conocimiento nunca se presenta ante el entendimiento como lo absolutamente extraño. Ni tan siquiera en lo que concierne a los cuerpos que, naturalmente, son de índole distinta a la razón y que, sin embargo, llega ésta a conocerlos en su verdadera esencia por cuanto en ellos hay de razonable, es decir, en

16 Soliloquios, I, 2, 7

17 Fernandez Rañada, F. Los cientificos y Dios. Oviedo, Nobel, 1994, pag. 165.

18 De la cuantidad del alma, 23, 44

19 Escribe Unamuno en su diario íntimo: El proceso del Cristianismo se debió a las enseñanzas de Cristo ayudadas providencialmente por la filosofía helénica. Si los profetas de Israel fueron los anunciadores del mesías, la filosofía helé-

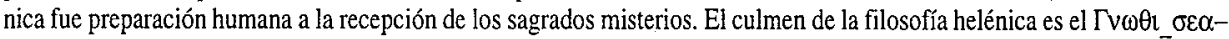
tov del templo de Delfos. La mística cristiana ha dado mayor lucidez y profundidad a este gran consejo del oráculo, y los grandes místicos castellanos glosan y ponderan de mil modos el conócete a ti mismo, y aún más el conóceme, Señor, a mí y conocerte he a ti». Oroz Reta, J. El agonismo cristiano. Salamanca, Universidad Pontificia de Salamanca, 1986, pag. 24. 
cuanto que son criaturas divinas y como tales dotadas de una forma, de un modo y de una medida; en definitiva, de una ratio que en última instancia remite a una Razón Suprema que no ha creado nada sin orden. Conocemos no porque el pensamiento dote de una forma a la materia sino porque las cosas están configuradas según un orden. De manera que si el conocimiento de las cosas es posible, cuánto más lo será el de la propia razón en tanto que el grado de afinidad y cercanía entre sujeto y objeto es mayor, es más, no existe cercanía sino identidad. En este nivel de conocimiento la simpatía es plena.

Por el mismo argumento puede legitimarse el conocimiento de Dios, aunque con un alcance limitado, en la medida en que podemos conocer a Dios, o de Dios, por aquello con lo cual somos semejantes a él, aunque en grado muy inferior. Esto que nos hace semejantes a Dios no es otra cosa que el alma racional, lo específicamente humano, aquello que nos distingue y nos hace superiores al resto de las criaturas.

En pocas palabras, podemos afirmar que el conocimiento tanto de las cosas como de Dios, sólo es posible en tanto que son razonables y únicamente en ese aspecto pueden coincidir con nuestro entendimiento racional. Hay que hacer, sin embargo, la puntualización de que Dios, siendo como es superior al hombre, se presenta como naturaleza en cierto modo extraña a nosotros y aquí se abre una brecha, un distanciamiento por el que ese conocimiento será siempre, mientras seamos criaturas mudables, limitado y aproximativo.

Por lo que respecta a las cosas creadas, éstas no suponen, en principio, un problema para el conocimiento, al menos no en el sentido de que ellas presenten una resistencia ontológica a ser conocidas. En todo caso, el problema de su conocimiento vendría dado por una negativa del hombre a conocer lo real de las cosas, dado el carácter mudable de la razón humana que a menudo se pierde tras los pasos de la sensibilidad, sin percatarse de que su fundamento es siempre de naturaleza estrictamente transcendental y su conocimiento, intelectual y no sensible. Por lo tanto, la extrañeza de los cuerpos con respecto al entendimiento no es tanta si tenemos en cuenta que conocerlos verdaderamente es aprehender lo que en ellos hay de racional. Y, por otra parte, la superioridad del individuo frente a las cosas le coloca en una situación privilegiada que le permite acceder a su conocimiento.

No obstante, hablemos de las criaturas no humanas y hablemos de Dios. En ambos casos se trata de algo que no es lo mismo que el hombre. De ahí se concluye que el autoconocimiento, como conocimiento del alma racional, puede concebirse como el conocimiento más fiable, pues la verdad en este terreno consistiría en la adecuación del entendimiento consigo mismo. De aquí podría colegirse un excesivo optimismo cognoscitivo que es, sin embargo, negado por San Agustín desde el momento en el que él reconoce que no se conoce a sí mismo. ${ }^{20}$ Efectivamente, el autoconocimiento no es fácil, puesto que requiere de toda una vida dedicada a la introspección y a la virtud, vida, por lo demás, a la que muy pocos hombres están dispuestos a consagrarse y, aún haciéndolo, el éxito no está garantizado.

Un nuevo interrogante se suscita de lo dicho hasta ahora, si tenemos en cuenta que la razón conoce por afinidad con lo que de racional encuentra en su objeto: ¿hay algún conocimiento que 
no consista en una adecuación del entendimiento consigo mismo? En cierto modo así parece ser, si consideramos que la razón, cuando conoce, no sale de sí misma, es decir, conoce de un objeto lo que hay en él de razón, de manera que se produce una identidad entre la razón y el objeto. Se trataría, en definitiva, de una especie de autocontemplación. No obstante, esto sólo es así si no tenemos en cuenta los sentidos que de razón distingue el santo. Así, no podemos hacer equivaler lo razonable con la razón, ${ }^{21}$ esto es, no es el mismo significado que tiene el vocablo razón cuando San Agustín lo refiere al orden apreciable incluso en la más insignificante de las criaturas, que el sentido otorgado a esa Razón Superior identificada con Dios y que es la que ha hecho razonables a todos los seres. Tampoco es unívoco el término razón atribuido al hombre, dado que la razón común presente en todos los hombres es diferente de la razón superior con la que se tiene acceso a la verdadera realidad transcendente, aunque en ambos casos se hable de una misma razón, más primitiva y más elaborada respectivamente, y que se refiere en última instancia a la Razón Suprema. Como puede apreciarse se están barajando distintos niveles que permiten, cuando menos, una separación entre conocedor y objeto de conocimiento, de manera que no puede afirmarse que el conocimiento es siempre adecuación del entendimiento consigo mismo en un sentido absoluto. En otros términos, el hombre cuando conoce un objeto, no está tratando de conocer la misma razón sino algo que de suyo es razonable, es decir, hecho con razón, pero es por ese su carácter razonable por lo que puede ser conocido por una razón.

Volviendo al autoconocimiento, decíamos que en éste el entendimiento tiende a adecuarse consigo mismo. Esta idea puede sugerir la imagen de una razón en plena quietud, que se limita a asentir a sí misma en su autocontemplación. Nada más lejos de la realidad; tal imagen podría ser atribuida en todo caso a Dios, teniendo en cuenta su omnipotencia y su omnisciencia, pero en el caso del sujeto el conocimiento de su alma se presenta como un proceso doloroso y conflictivo, tal como nos lo hace constar San Agustín en sus plegarias a Dios para que ilumine su oscuro entendimiento. Se puede constatar incluso en sus dudas y en las equivocaciones en las que incurre antes de llegar a la resolución del problema planteado. Hay que partir de un supuesto, el carácter ontológicamente deficitario del ser humano. Por ello, la razón, a pesar de que el hiponense la valora muy positivamente, está lejos de ser esa facultad cuasiilimitada en sus posibilidades cognoscitivas que nos presentó el racionalismo ilustrado; al mismo tiempo, difiere infinitamente de esa otra razón divina inmutable en cuyo seno no caben la contradicción y el error.

La razón humana está sujeta a un proceso discursivo, dialéctico, en un sentido platónico, a una pugna interna que expresa sabiamente nuestro autor en el diálogo entablado con su razón en los Soliloquios. Ese proceso de pregunta-respuesta que la razón provoca en sus indagaciones es expresado didácticamente en forma de diálogo ficticio, aunque estrictamente real por cuanto representa el propio diálogo interior.

Los dos personajes San Agustín y la razón, interpretan a su vez dos papeles referidos a un solo acto, el de la razón escudriñándose a sí misma, y a su movimiento discursivo, en el que se duda, se interroga, se afirma, etc. San Agustín interpreta el papel del discípulo y su habilidad retórica acentúa ese carácter de aprendiz en sus dudas manifiestas, en sus incoherencias e incluso en las amonestaciones a las que se ve sujeto por parte de una razón que interpreta el papel de guía o maestro. Se 
Se presenta, por tanto, una dualidad que nos viene a recalcar nuevamente la idea de que sólo en la serena razón divina se da plena identidad y unidad. Pero, al mismo tiempo, esta imagen nos advierte que la razón, a pesar de su necesario proceso interrogativo, nos da respuestas firmes. Ese carácter en cierto modo autoritario de la razón que dialoga con San Agustín revela que aquélla posee la verdad y que ésta es comunicable, aunque su consecución está precedida de una lucha. Se incide, en este aspecto, en que no sólo el autoconocimiento es posible, sino que además la vía interior, el análisis racional, es el único que puede dar respuestas porque éstas están ya en ella. Por otra parte, Dios ilumina la mente del hombre para que pueda conocerlas, es decir, se requiere de un tercer elemento entre el sujeto y el objeto para que el conocimiento sea posible, y este tercer elemento es el mismo Dios. No es, por lo tanto, extraño que San Agustín invoque constantemente a Dios solicitando su auxilio para alcanzar la sabiduría.

\section{LÍMITES DEL CONOCIMIENTO RACIONAL}

Los Soliloquios parten del profundo interés, teórico pero también vital, por el conocimiento acerca de aquello que hay en el hombre de más excelente: el alma; y acerca del fundamento tanto del alma como de todo cuanto existe: Dios.

El conocimiento de Dios y del alma van a ocupar buena parte de las consideraciones del santo por las implicaciones religiosas, cognoscitivas y éticas que tiene. Dios y el alma aparecen íntimamente ligadas desde el comienzo del escrito, y no es ésta una conexión casual sino que responde, por una parte, a dos objetos de conocimiento que transcienden toda materialidad y para cuyo conocimiento se requiere de un ánimo peculiar, cerrado a influencias externas que alimentan a la sensibilidad, para centrarse en la pura razón. Pero además de la proximidad de ambos conceptos, por su índole espiritual, hay otro motivo aún más profundo, y es que a través del conocimiento del alma va a encontrar San Agustín la base intelectual necesaria para justificar la existencia de Dios. No obstante, esta obra deja esta temática inconclusa, deteniéndose en su camino ascensional en el tema de la verdad, concretamente en la inmortalidad de ésta como condición de posibilidad de la inmortalidad del alma, quedando así el conocimiento de Dios postergado y no olvidado, dada la tremenda envergadura de estas investigaciones que ni tan siquiera se dan por concluidas en lo que respecta al conocimiento del alma.

Dada la actitud religiosa de San Agustín, no es sorprendente que estos dos temas ocupen buena parte de su producción literaria. Sin embargo, no hay que olvidar que el tratamiento es netamente filosófico, por cuanto la pretensión es la de alcanzar estos conocimientos por la razón. San Agustín evidentemente cree en la existencia del alma y de Dios. Pero la fe no basta; él siente la necesidad de conocer, de entender. Le plantea la razón a San Agustín la posibilidad de que sus anhelos cognoscitivos sean saciados con lo que a propósito del tema han dicho Platón y Plotino. Sin embargo, él muestra enseguida su desconfianza, alegando que estas verdades no necesariamente han sido descubiertas por aquéllos «con ciencia». ${ }^{22} \mathrm{Y}$ aquí deja suficientemente claro nuestro autor que sus reflexiones pretenden alcanzar el rango de científicas, entendiendo por tales aquéllas que se han 
seguido de un razonamiento que nos muestra sus conclusiones con el mismo grado de certeza que existe en las verdades matemáticas. El ideal numérico de claras resonancias pitagóricas es empleado por Agustín para referirse a ese mundo de certezas inmutables que, no obstante, posee la verdad en virtud de esa otra Verdad absoluta que es Dios. Pero hasta llegar al conocimiento o intelección de Dios, es consciente el retor de que sus aseveraciones acerca de la naturaleza divina, incluyendo las atribuciones y adjetivaciones de Dios expresadas en las plegarias, no responden a otra cosa que a la creencia. El autor se confiesa, por lo tanto, ignorante respecto de Dios y del alma, lo que no es óbice para que pueda hablar de ellos basándose en la fe. Así pues, el hiponense se aleja radicalmente de actitudes que, ante la incognoscibilidad de Dịos optan por el silencio amparándose en su inefabilidad. Si en algunos pasajes se alude a la inefabilidad divina se hace con la intención de subrayar su omnipotencia y la superioridad de ésta frente a la precariedad humana.

Dios, desde el punto de vista agustiniano, no es totalmente inefable por dos motivos: en primer lugar, porque la creencia o fe nos legitima para hablar de él, y en segundo lugar porque, aun reconociendo el santo su ignorancia, no dice que a Dios no se le pueda conocer en absoluto: «Pues te promete la razón, que habla contigo, mostrarte a Dios». ${ }^{23} \mathrm{Al}$ menos a Dios se le puede mostrar y por ello se puede hablar de él con sentido. Sin embargo hay que tener presente que tal vez esta excesiva confianza en las posibilidades de la razón responde al entusiasmo de sus primeros escritos; avanzando en edad y en madurez religiosa e intelectual San Agustín va a ir matizando esta idea poniendo cada vez más el acento en la fe como medio de acercamiento a la naturaleza del Creador, aunque sin negar la necesidad del intelecto. En este orden resulta esclarecedor un texto muy significativo en De la utilidad del creer, según el cual, en el conocimiento se da primacía a la fe porque inevitablemente ésta ha de estar presente en los inicios de toda investigación acerca de cuestiones de índole transcendente, ${ }^{24}$ es más, no sólo lo está en los inicios, sino que acompaña a toda la investigación de principio a fin. Sin embargo, hay que tener en cuenta que este texto, en línea claramente agustiniana, incluye una buena dosis de contenido apologético y de crítica contra las desviaciones heréticas, una de las cuales consistía en dar primacía a la razón ofreciendo a sus seguidores conocimientos y no meras creencias, a la par que se atacaba a la Iglesia Católica por exigir la fe a sus fieles. San Agustín, como es lógico, se ve en la necesidad de ofrecer un contrapeso a tales argumentaciones y abunda en la importancia de la fe, evidente por otra parte, pero en textos anejos se demuestra con claridad meridiana que es la pura razón la que ha de llevar a buen fin el conocimiento de la verdad. Es más, el problema para inteligir lo transcendente parece a menudo que viene dado no por la propia razón, sino por la incapacidad, habitual en el hombre, para conducirla correctamente. ${ }^{25}$ Se insiste, en este aspecto, en que es la razón —en un sentido no cientista— la única facultad que puede acceder al conocimiento de Dios.

Y no resulta descabellada o irracional la pretensión del santo por conocer el alma y a Dios: «Es razonable tu interés», ${ }^{26}$ le asegura la razón, es decir, cabe dentro de la lógica esta pretensión. La frase aludida viene a hacer hincapié en el carácter estrictamente intelectual de la búsqueda agusti- 
niana. No se trata, por tanto, de un intento por dotar de razón a algo que de suyo es irracional; por el contrario, la problemática a la que nos enfrenta tiene plena legitimidad desde las coordenadas de la pura racionalidad. En este aspecto, podría desmentirse la aseveración unamuniana presente en Del sentimiento trágico de la vida, de que San Agustín se encontraba entre ese grupo de grandes hombres trágicos que anhelaban dar respuesta a una motivación irracional, entendiéndose por ello la inmortalidad del alma. ${ }^{27}$ Efectivamente, Unamuno se debatía entre una razón que le hablaba de la imposibilidad de una vida más allá de la muerte física, y su necesidad de creer en la inmortalidad; en otros términos, se trataba de su resistencia a admitir que algún día dejaría de ser. Si bien es cierto que la cuestión de la inmortalidad del alma es de radical importancia en los escritos de San Agustín no creemos que pueda explicarse su tragedia en estos términos, al menos tras su conversión a la fe católica. En todo caso, el dolor que acompaña al santo a lo largo de su camino interior, que es al mismo tiempo un progreso intelectual, se debe a la plena creencia de que el conocimiento del alma, de su inmortalidad y, a la postre, de Dios, es legítimo racionalmente y además posible en cierto grado, pero advierte cierta impureza que le impide ver con nitidez; se siente, por así decirlo, indigno ante los ojos de Dios y en este aspecto considera necesario el constante auxilio divino para que ilumine su razón capacitándole para aprehender intelectualmente lo que ya posee por creencia. En definitiva, no se trata de racionalizar lo irracional, sino de formular coherentemente una creencia que de suyo es razonable. Parece aquí el santo sugerir la idea de que si la creencia se racionaliza se seguiría su realidad, realidad de la que de antemano no duda pero que si logra deducirla lógicamente se habría colmado, por una parte su misión apologética y, por otra, se hallaría más cerca del ideal del sabio capaz de descubrir la verdad con ciencia.

Se puede afirmar que la razón está presente desde los inicios de la investigación y no sólo en sus conclusiones. La creencia que actúa a modo de hipótesis ya está impregnada de una racionalidad germinal que habrá de desplegarse a posteriori plenamente. Creemos, por tanto, porque la creencia resulta plausible, y en este sentido, racional; pero, al mismo tiempo, esta creencia es condición de posibilidad para superar el estadio de la mera creencia logrando la certidumbre del saber.

A la luz de estas consideraciones, ¿puede afirmarse que el saber elimina a la fe? Evidentemente para San Agustín esto no es así. El saber adquirido alimenta a la fe en una naturaleza de índole espiritual que no llega a conocerse plenamente en vida. La fe, por tanto, es enriquecida por el entendimiento y no aniquilada por éste. Admitiría así una doble lectura la conocida formula agustiniana intellige ut credas, crede ut intelligas. Creer para entender se refiere a ese nivel básico de creencia — que no deja de incluir un nivel básico de racionalidad - imprescindible para alcanzar el conocimiento. Efectivamente, el científico no comienza una investigación si no cree en la hipótesis de partida. De modo similar puede entenderse la tarea de San Agustín, una tarea que va acompañada de las tres virtudes teologales: fe, esperanza y caridad. La fe en el objeto del conocimiento y en un Dios que habrá de limpiar sus ojos para que sean aptos para la contemplación de la verdad; la esperanza en que puede alcanzarse ese conocimiento y la caridad, en su sentido originario de amor, que mantiene al investigador unido a su trabajo científico. Estas tres virtudes no son abandonadas una vez que se ha alcanzado el conocimiento, sino que acompañan y refuerzan a éste. Unicamente tras la muerte, cuando el alma se una a Dios, la fe y la esperanza serán superadas per- 
maneciendo exclusivamente la caritas. Mientras tanto, dada la naturaleza deficitaria del ser humano y el carácter mudable de la razón, el conocimiento debe ir ineluctablemente ligado a la fe. Así pues, la creencia es la base para el entendimiento, pero al mismo tiempo, el entendimiento es la base para la fe; se trata de creer para inteligir, y de inteligir para creer, en el aspecto señalado más arriba de que por que son razonables las creencias, porque hay en ellas intelección, las asimilamos; al mismo tiempo, porque el entendimiento alcanza verdades que transcienden nuestra finitud, nutre nuestra fe y apuntala una razón deficitaria.

\section{LA VIGENCIA DE LA RAZÓN EN EL CONOCIMIENTO DE DIOS}

La fe y la razón son, por lo tanto, los dos medios de conocer a Dios. En cuanto a la primera, no cabe la menor duda, puesto que a menudo se entiende que a Dios le conocemos mediante la fe. Más difícil es admitir un conocimiento de tipo racional - e incluso se llega a cuestionar el hecho de que se trate, en efecto, de algún conocimiento. Se han perfilado vías de acceso directo a la divinidad y, en este sentido se podría hablar de un tipo especial de conocimiento- a través de métodos, si no irracionales sí al menos arracionales, que han dado prioridad a la intuición asociándola a la emotividad, atendiendo a que la finitud de la racionalidad humana no puede aprehender la infinitud divina porque la transciende. Como ya se ha indicado con anterioridad, la línea marcada por San Agustín es bien distinta, aún sin negar, en este punto, que él es plenamente consciente de las limitaciones del ser humano y de que está tratando de una realidad que le supera. Dada la humildad que caracterizó al hiponense, resulta imposible asociarle a un tipo de racionalismo soberbio que pretendiera conocer a Dios sin problemas, partiendo de los precarios medios de los que el hombre dispone. No obstante, el santo se refiere al conocimiento de Dios y, como se ha visto, en sus textos se evidencia que la razón desempeña un papel fundamental en él. Baste recordar una frase ya citada «te promete la razón que habla contigo mostrarte a Dios». De ser esto cierto, parece que la intelección de Dios es más que posible. Lógicamente, no podemos demostrar la existencia de Dios tal como demostramos la existencia de los átomos porque no estamos ante un objeto de naturaleza material, lo que no es inconveniente para especular y hablar sobre ello; no estamos tratando con un tipo de razón factual que se atiene únicamente a los datos aportados por la empiría. Se podría aducir que el sentimiento estético o los valores morales no son palpables y no por ello son negados, y no lo son porque experimentamos su existencia a un nivel no empírico. Pero resulta que a Dios también se le experimenta, no sólo individualmente, sino en comunidad; las profundas emociones del hiponense son más que explícitas en este punto, viéndose ante la necesidad vital de explicar racionalmente a ese Dios que experimentaba como el ser donde se reúnen todas las perfecciones de forma excepcional.

Suponer que a Dios no se le puede pensar es debido a que se parte de un modelo de racionalidad reduccionista que se atiene exclusivamente a lo sensible. Que no se puede demostrar su existencia como se demuestra la de un objeto sensible es evidente; demostrarlo, para San Agustín, es justificar coherentemente la creencia en él. Se parte aquí de un supuesto, pero, al fin y al cabo, todo pensamiento parte de supuestos, sea o no consciente de ellos. En este caso, el supuesto en el que se apoya Agustín nace de una percepción que no tiene un asiento sensible a no ser el de la grandeza que observa en la armonía del universo a la que juzga ordenada por una mente divina: en la belleza de la creación escucha el joven Agustín una voz que le habla de Dios. 
Las pruebas para demostrar la existencia de Dios van enfocadas a su inteligibilidad, esto es, a hacerlas racionales de tal manera que pensar a Dios caiga dentro de los límites de la legitimidad racional, para concluir que la existencia de Dios es una verdad de razón. Es aquí donde San Agustín da el paso decisivo que le hace colegir de su intelección su existencia, es decir, si Dios es razonable también es real. El hiponense concluye la existencia divina basándose en su razonabilidad ateniéndose al ambiente platónico que envuelve su obra: la idea platónica está dotada de una existencia transcendente pero plenamente real y objetiva a la que sólo se tiene acceso por la razón. De modo paralelo, podría aducirse que San Agustín, cuando argumenta racionalmente cree estar captando ideas que poseen plena existencia real aunque transcendente. Las ideas de razón, por lo tanto, y dentro de un esquema platónico, no están carentes de contenido, sino que se refieren a objetos sin existencia espacio - temporal; hay un sustrato de realidad no perceptible que fundamenta tales razonamientos. De este modo, si la razón es real, el que la creencia en Dios sea racional la convierte ipso facto en real.

Sólo fuera de un prisma platónico tales razonamientos se considerarían sin fundamento, en tanto que carentes de contenido efectivo. En este caso las argumentaciones agustinianas no serían más que un juego retórico de creación de ideas e imágenes cuyo valor de verdad no iría más allá de la mera literatura. Sin embargo, desde la óptica platónico-agustiniana, no hay una creación de ideas porque éstas ya están dadas de antemano, lo que hay es un desvelamiento, una re-creación que se lleva a cabo, con toda legitimidad, desde una racionalidad finita. El pensamiento sobre Dios, por lo tanto, se desenvuelve, en este contexto, dentro de la legitimidad racional, a pesar de las dificultades propias de una razón ontológicamente deficitaria.

\author{
Almudena Jiménez Manzanas \\ Facultad de Filosofía-Universidad de Salamanca \\ Departamento de Filososfía y Lógica \\ y Filosofía de la Ciencia \\ Campus Unamuno. Edificio F.E.S. \\ 37007-Salamanca \\ Almudena@gugu.usal.es
}

